Portland State University

PDXScholar

$5-24-2018$

\title{
The Effect of Light Exposure on the Total Chlorophyll Content, Chl a/b Ratio, and Car/chl Ratio in the Barks of Fraxinus latifolia Seedlings
}

Trang T. Tran

Portland State University

Follow this and additional works at: https://pdxscholar.library.pdx.edu/honorstheses

Let us know how access to this document benefits you.

\section{Recommended Citation}

Tran, Trang T., "The Effect of Light Exposure on the Total Chlorophyll Content, Chl a/b Ratio, and Car/chl Ratio in the Barks of Fraxinus latifolia Seedlings" (2018). University Honors Theses. Paper 575.

https://doi.org/10.15760/honors.583

This Thesis is brought to you for free and open access. It has been accepted for inclusion in University Honors Theses by an authorized administrator of PDXScholar. Please contact us if we can make this document more accessible: pdxscholar@pdx.edu. 
The Effect of Light Exposure on the Total Chlorophyll Content, Chl a/b Ratio, and Car/chl Ratio in the Barks of Fraxinus latifolia Seedlings

by

Trang T. Tran

An undergraduate honors thesis submitted in partial fulfillment of the

requirements for the degree of

Bachelor of Science

in

University Honors

and

Science

Thesis Adviser

Daniel J. Ballhorn

Portland State University 


\section{ABSTRACT}

The purpose of this study is to determine the effect of light exposure on the total chlorophyll content, the chl a/b ratio, and the car/chl ratio and thus the shade tolerance of Fraxinus latifolia. Stems of Fraxinus latifolia seedlings were applied with aluminum foil for the $0 \%$ light exposure treatment, with shade cloth for the $50 \%$ light exposure treatment, and left uncovered for the $100 \%$ light exposure treatment. Chlorophyll from barks were extracted using $80 \%$ acetone and spectrophotometric analysis was carried out. The results revealed that in the 8-week samples, the $100 \%$ light exposure treatment showed the highest total chlorophyll content, inconsistent with the general trend that chlorophyll content increases under low light condition, but in the 4-week samples, the 50\% light exposure treatment showed the highest total chlorophyll content. Consistent with shade characteristic, the chl a/b ratio of the $50 \%$ light exposure treatment was significantly lower than that of the $100 \%$ light exposure treatment in the 8 -week samples. However, the reverse result was observed in the 4-week samples. Although the car/chl ratio of the $0 \%$ light exposure treatment was significantly lower than that of the $50 \%$ light exposure treatment in the 8 -week samples, stems with 50\% light exposure showed a significantly higher car/chl than those with 100\% light exposure, inconsistent with shade characteristic. Remarkably, the results obtained challenge the general application of the shade tolerance criteria as the status of other environmental factors occurring over different time periods can influence shade tolerance. 


\section{INTRODUCTION}

Previous research has shown that not only are green leaves capable of photo-reducing carbon dioxide, but other plants parts, such as petioles, green flowers, calyces, green fruits, cones, stem tissues, and roots are also capable of carrying out photosynthesis (Pfanz et al., 2002; Nilsen, 1995). In fact, spectrophotometric analysis demonstrated that the green pigment in quaking aspen bark is chlorophyll (Strain and Johnson, 1963). Therefore, the first type of photosynthesis is characterized by net photosynthetic assimilation using atmospheric carbon dioxide and is associated with leaves, green stems, and green sterile flower organs; the second type is characterized by internal carbon dioxide recycling using respired carbon dioxide and is associated with bark and wood tissues, fruit, root, and fertile flower organs (Aschan and Pfanz, 2003). Photosynthesis in the bark reduces woody-tissue respiration, thereby increasing the efficiency with which trees convert photosynthetically reduced C into new biomass (Cernusak and Marshall, 2000). Since bark cortex contains photosynthetic tissue that is responsible for the internal re-fixation of carbon dioxide, the process is referred to as corticular photosynthesis (Simbo and Samson, 2013).

Corticular photosynthesis or bark photosynthesis has been reported to occur in a wide variety of plants (Schaedle, 1975). The effects of variation in temperature and light as well as morphological and physiological traits were studied in Western White Pine, Pinus monticola (Cernusak and Marshall, 2000); studies on the temperature dependencies of stem dark respiration and bark photosynthesis in beech (Fagus sylvatica) and birch (Betula pendula) were investigated (Wittmann, 2007); another study investigated winter corticular photosynthesis in four deciduous 
species: dogwood (Cornus fiorida), red maple (Acer rubrum), white oak (Quercus alba), and yellow-poplar (Lirio-dendron tulipifera) to compare photosynthetic activity of leafless twigs of species with varying shade tolerances and the significance of changes in the chlorophyll content of twigs during the winter (Coe and McLaughlin, 1980); moreover, research was done on the age-dependency of stem-internal carbon re-fixation as well as morphological and physiological parameters in Eurasian aspen bark (Aschan, 2001).

Wittmann et al. (2001) aim to demonstrate the effectiveness and the adaptive significance of stem-internal carbon re-fixation in a high light-preferring pioneer tree, Populus tremula, and a shade-preferring forest tree, Fagus sylvatica, that were grown under different light regimes. Chlorophyll contents of young beech twigs were higher under low light conditions, and chlorophyll $\mathrm{a} / \mathrm{b}$ ratios of the bark were similar to those of shade-adapted leaves. In addition, chlorophyll $\mathrm{a} / \mathrm{b}$ ratios of the bark chlorenchyma were lower as compared to the leaves, possibly due to the shading effect of the outer cork layers which reduces light penetration. Within current-year branch of Populus tremula, the chlorophyll content of bark chlorenchyma was age-dependent. Peridermal light transmission was higher in current-year beech twigs than in one-year-old twigs, suggesting that using juvenile plants to study corticular photosynthesis is ideal.

The aim of the study in "Carotenoid Composition of Peridermal Twigs Does Not Fully Conform to a Shade Acclimation Hypothesis" by Levizou et.al. (2004) was to analyze carotenoid content in twigs and determine if the twig carotenoid profile is in agreement with the shade acclimation 
hypothesis. The study found that chlorophyll $(\mathrm{Chl}) \mathrm{a} / \mathrm{b}$ ratios in twigs were consistently low, consistent with what is typically found in shade leaves. However, the carotenoid contents were high, thereby indicating that the twig chlorenchyma resembles more of a sun than a shade type of photosynthetic tissues. A possible explanation for this discrepancy is that high $\mathrm{CO}_{2}$ stress within the stems can increase the need for enhanced photoprotective non-photochemical quenching even at low irradiance.

In spite of the winter season, it is suggested that the synthesis of chlorophyll in the bark does occur (Bar and Potter, 1974). According to Schaedle (1975), the presence of chlorophyll and chloroplasts in bark does not necessarily indicate the presence of photosynthesis. Nevertheless, Gundersen (1954) noted that the chlorophyll a/b ratio of beech bark aligns with the ratio normally found in photosynthesizing tissues, confirming the fact that bark of trees exposed to light re-fix carbon dioxide released by respiration of living cells in bark. One of the primary factors that affect the content of photosynthetic pigments and their quantitative composition is light (Tokarz and Pilarski, 2005). When considering twig or branch photosynthesis, data on the chlorophyll content of twigs and branches are of great importance (Wittmann et al., 2001). Furthermore, the ability of plants to adapt to light stress helps plants maintain optimal rates of photosynthesis and function efficiently under limited light (Anderson et al., 1995; Beneragama and Goto, 2011). Photosynthetic structures of plants adapt to low light environment, and shade tolerance is an adaptive strategy that photosynthetic organisms exhibit in response to low light. Shade tolerance is characterized by physiological traits such as an increase in chlorophyll content and a decrease in chl a/b ratio (Valladares and Niinemets, 2008). Significantly, given that 
deciduous trees shed their leaves during the winter and thus are unable to perform photosynthesis via their leaves, the ability to increase chlorophyll content in barks under low light condition would indicate the ability of deciduous species to adapt to light stress.

Ash is a common deciduous tree species found throughout the climatic range of beech and overgrows and out-competes beech when resources are high through high growth rates, tall stature, and lateral spread above and below the ground (Einhorn, 2007). Fraxinus latifolia is the only ash native to the Pacific Northwest (Owston, 1990). Additionally, ash is known to be shade tolerant as young seedlings (Petritan, Von Lüpke, Petritan, 2007). However, little is known about how the stem of Fraxinus latifolia adapts to varying light exposure, specifically to low light condition, with respect to the standard criteria characterizing shade tolerance. In essence, the present study aims to determine the total chlorophyll content, chl a/b ratio, and the car/chl ratio in the barks of Fraxinus latifolia seedlings treated with $0 \%$ light exposure, $50 \%$ light exposure, and $100 \%$ light exposure for various periods of time ( 8 week, 4 weeks, and 2 weeks). The ability of Fraxinus latifolia barks to increase chlorophyll content under low light conditions and decrease chl a/b ratio will imply that Fraxinus latifolia is shade adapted, similar to shade leaves. A low car/chl ratio in samples subjected to low light conditions would be characteristic of shade chloroplast. Furthermore, contradictory results across the different time periods would challenge the general application of high chlorophyll content, low chl a/b ratio, and low car/chl ratio as criteria for shade tolerance, as other environmental factors occurring over the different time periods can influence shade tolerance. 


\section{MATERIALS AND METHODS}

\section{Samples}

Barks used in the experiment were obtained from the stems of Fraxinus latifolia seedlings grown in a raised bed located outside of the Portland State University research greenhouse. Three different treatments were applied to the stems: (1) $0 \%$ light exposure (stems were wrapped in aluminum foil), (2) 50\% light exposure (stems were wrapped in 50\% shade cloth), and (3) 100\% light exposure (stems were completely exposed to sunlight; control). Each treatment consisted of five replicates. The first 15 stems were applied with the three different treatments for 8 weeks. An additional 15 stems were applied with the three different treatments for 4 weeks, and another 15 stems were applied with the three different treatments for 2 weeks. Thus, a total of 45 stems were used. The 8-week samples were tested on February 9, 2018; the 4-week samples were tested on March 9, 2018, and the 2-week samples were tested on March 23, 2018.

\section{Chlorophyll Extraction}

The method for chlorophyll extraction was followed as described by Girma et al. (2013) but was slightly modified. A caliper was used to measure the length of the stems and a razor blade was used to scrape the barks off the stems with lengths of approximately $118 \mathrm{~mm}-120 \mathrm{~mm}$. A mortar and pestle were used to grind the barks with $80 \%$ acetone and dry ice. Subsequently, the chlorophyll solutions were centrifuged in a refrigerated centrifuge and the supernatants removed. The chlorophyll solutions were extracted with $80 \%$ acetone and centrifuged three times with the first time for 20 minutes at 6,000 rpm, second time for an additional 20 minutes at 6,000 rpm, and the third time for 10 minutes at $10,000 \mathrm{rpm}$. Following the extraction, the chlorophyll 
solutions were transferred from the plastic microcentrifuge tube to a glass test tube wrapped in aluminum foil. Additional $80 \%$ acetone was added to the glass test tube to the $4 \mathrm{~mL}$ mark. The glass test tube was then placed in the ice bucket with the lid closed.

\section{Spectrophotometric Analysis}

The spectrophotometer was set at $646 \mathrm{~nm}$ and $80 \%$ acetone served as a blank. A glass test tube containing chlorophyll solution was placed in the spectrophotometer, which was then set at 750 $\mathrm{nm}$ to account for turbidity. Absorbance values of the chlorophyll solutions were determined at $663 \mathrm{~nm}, 646 \mathrm{~nm}$, and $470 \mathrm{~nm}$. Chlorophyll a content (chl a), chlorophyll b content (chl b), and total chlorophyll content (chl $(\mathrm{a}+\mathrm{b}))$ were calculated using the equations from Porra et al. (1989). The total carotenoids content (car) were calculated using the equation from Straumite et al. (2015). The equations used are outlined in Table $A$ below:

Table A:

\begin{tabular}{|l|l|}
\hline Content of Photosynthetic Pigments & Equations \\
\hline $\mathrm{Chl} \mathrm{a}(\mu \mathrm{mol} / \mathrm{L})$ & $13.71 \mathrm{~A}^{663.6}-2.85 \mathrm{~A}^{646.6}$ \\
\hline $\mathrm{Chl} \mathrm{b}(\mu \mathrm{mol} / \mathrm{L})$ & $22.39 \mathrm{~A}^{646.6}-5.42 \mathrm{~A}^{663.6}$ \\
\hline $\mathrm{Chl}(\mathrm{a}+\mathrm{b})(\mu \mathrm{mol} / \mathrm{L})$ & $19.54 \mathrm{~A}^{646.6}+8.29 \mathrm{~A}^{663.6}$ \\
\hline $\mathrm{Car}(\mu \mathrm{mol} / \mathrm{L})$ & $\left(1000 \mathrm{~A}^{470}-1.82 \mathrm{Chl} \mathrm{a}-85.02 \mathrm{Chl} \mathrm{b}\right)$ \\
\hline & 198 \\
\hline
\end{tabular}




\section{Statistical Analysis}

Mean chlorophyll and carotenoid contents as well as the mean chl a/b and car/chl ratios were calculated with standard deviations. A one-way ANOVA and LSD post hoc test were used to determine if the means for each treatment are significantly different from one another. A p-value that is less than 0.05 is considered to be statistically significant.

\section{RESULTS}

\section{Total Chlorophyll Content}

In the 8-week samples, stems with 100\% light exposure showed the highest total chlorophyll content followed by those with $0 \%$ light exposure and 50\% light exposure (Figure 1A); in the 4-week samples, stems with 50\% light exposure showed a significantly higher $(\mathrm{p}<0.001)$ total chlorophyll content than those with $0 \%$ light exposure and a significantly higher $(\mathrm{p}<0.001)$ total chlorophyll content than those with $100 \%$ light exposure, while no significant difference was observed between stems with $0 \%$ light exposure and those with $100 \%$ light exposure (Figure 1B). For the 2-week samples, no significant differences were observed between stems with $0 \%$ light exposure and the other two treatments and between stems with 50\% light exposure and those with 100\% light exposure (Figure 1C).

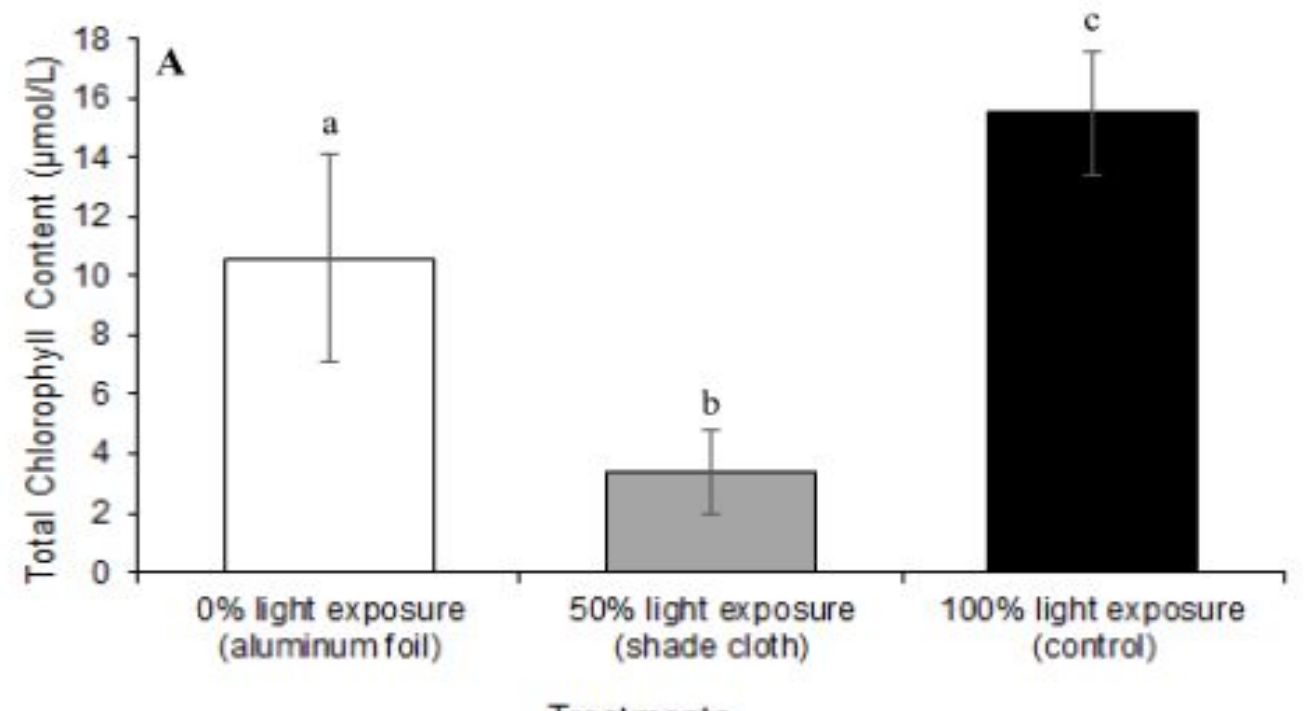



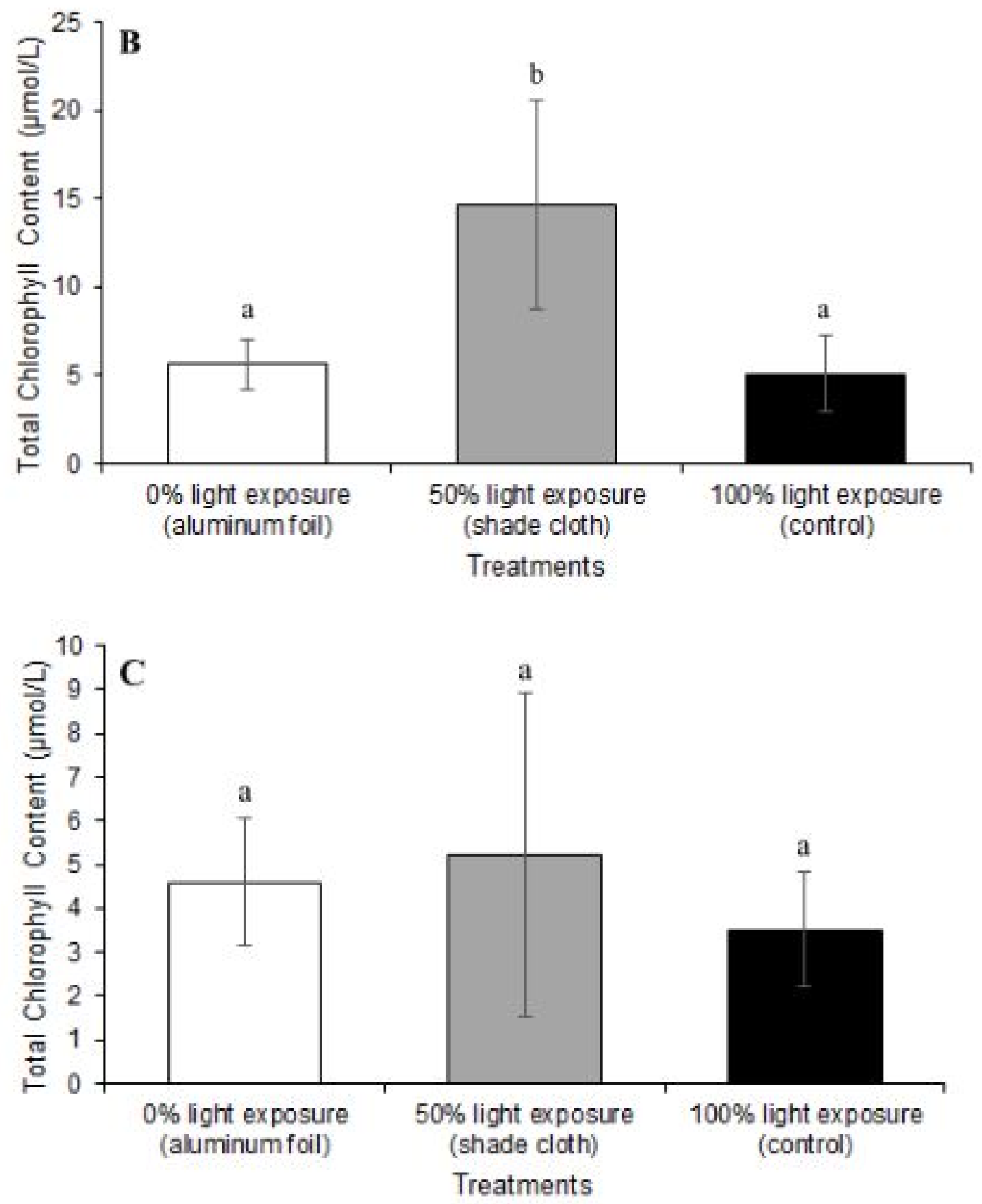

Figure 1: Mean total chlorophyll content $(\mu \mathrm{mol} / \mathrm{L})$ comparison between three different treatments ( $0 \%$ light exposure, 50\% light exposure, and 100\% light exposure) treated for (A) 8 weeks, (B) 4 weeks, and (C) 2 weeks. Standard deviation bars are included on each of the bar graph. Means sharing the same letter are not statistically significant at the 95\% confidence level based on the LSD post hoc comparison method. 


\section{Chlorophyll a to Chlorophyll b Ratio}

The chl a/b ratio of the $0 \%$ light exposure treatment in the 8 -week samples was significantly higher $(\mathrm{p}<0.001)$ than that of the $50 \%$ light exposure treatment but was not significantly different from the $100 \%$ light exposure treatment (Figure $2 \mathrm{~A}$ ). Additionally, the chl a/b ratio of the $50 \%$ light exposure treatment was significantly lower $(\mathrm{p}<0.001)$ than that of the $100 \%$ light exposure treatment (Figure 2A). Contrary to the aforementioned results in the 8-week samples, the chl $\mathrm{a} / \mathrm{b}$ ratios obtained for the three treatments in the 4-week samples showed the reverse: the chl $\mathrm{a} / \mathrm{b}$ ratio of the $0 \%$ light exposure treatment was significantly lower $(\mathrm{p}<0.001)$ than that of the $50 \%$ light exposure but showed no significant difference with the $100 \%$ light exposure treatment; furthermore, the $\mathrm{chl} \mathrm{a} / \mathrm{b}$ ratio of the $50 \%$ light exposure treatment was significantly higher $(\mathrm{p}=0.005)$ than that of the $100 \%$ light exposure treatment (Figure $2 B$ ). Similar to the results reported for the total chlorophyll content, no significant differences were observed between the three treatments in the 2-week samples (Figure 2C).

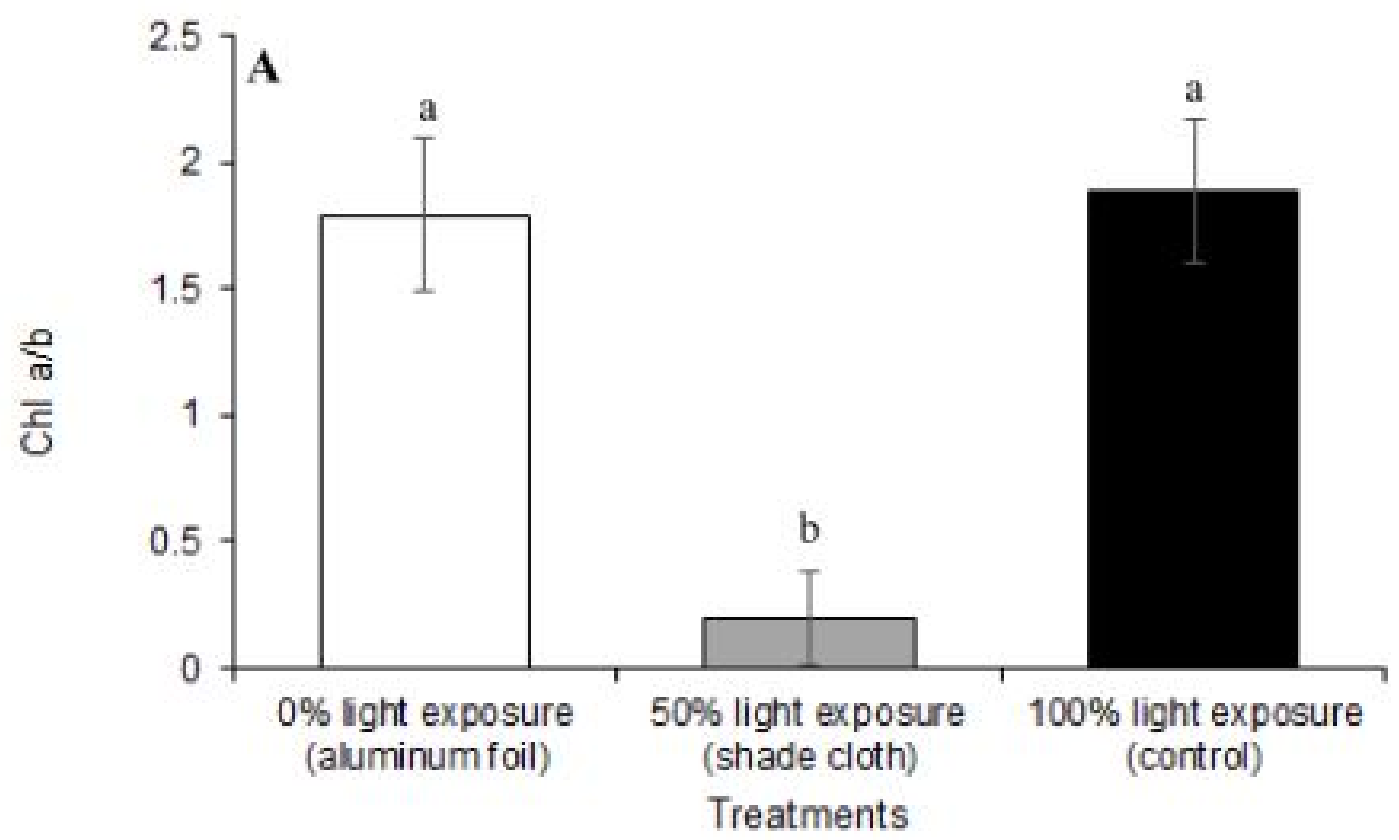



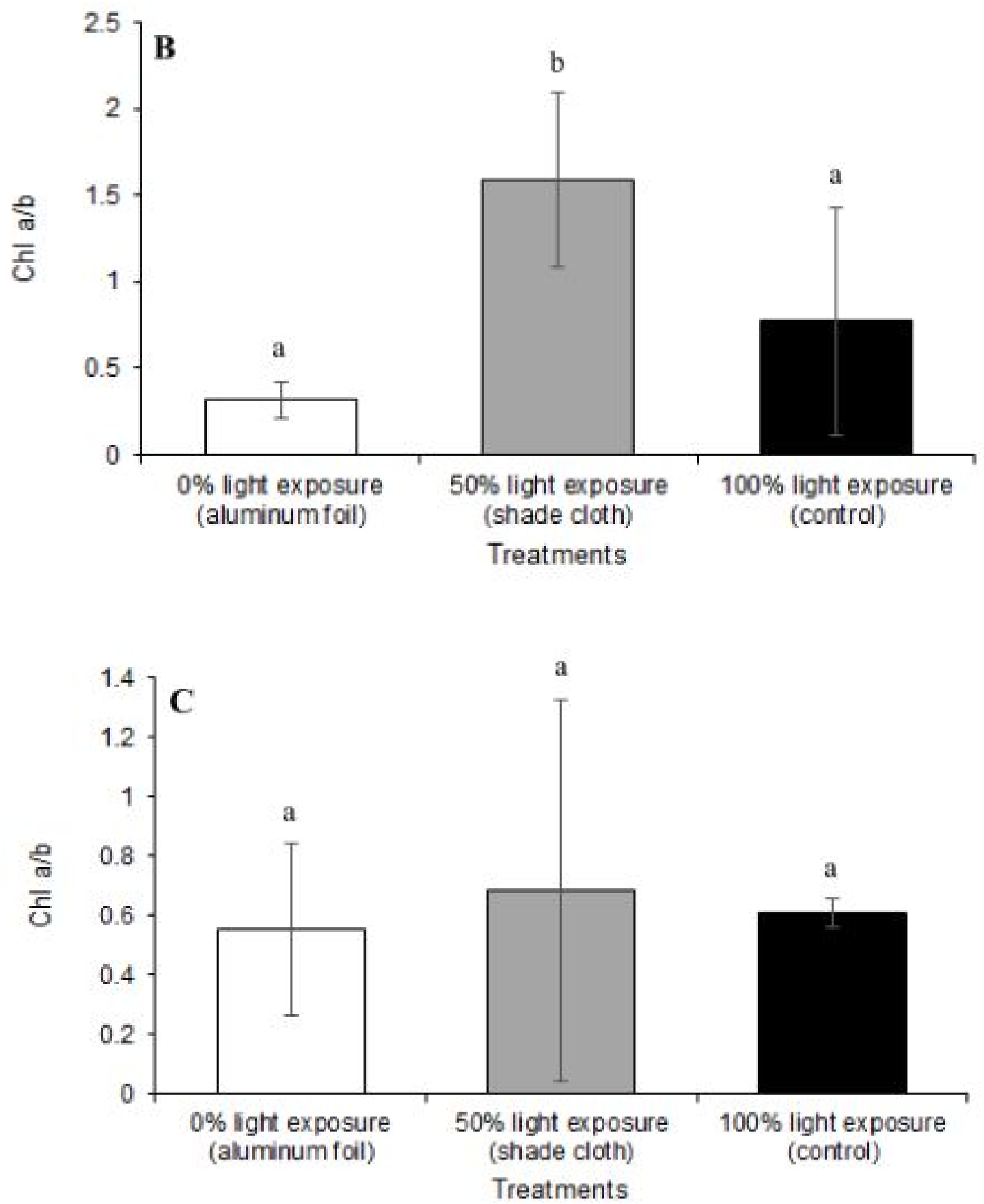

Figure 2: Mean chl a/b ratio comparison between three different treatments (0\% light exposure, $50 \%$ light exposure, and 100\% light exposure) treated for (A) 8 weeks, (B) 4 weeks, and (C) 2 weeks. Standard deviation bars are included on each of the bar graph. Means sharing the same letter are not statistically significant at the 95\% confidence level based on the LSD post hoc comparison method. 


\section{Carotenoid to Chlorophyll Ratio}

The car/chl ratio of stems with $50 \%$ light exposure in the 8 -week samples was significantly higher $(\mathrm{p}=0.001)$ than those with the $0 \%$ light exposure treatment and higher $(\mathrm{p}=0.002)$ than those with the $100 \%$ light exposure treatment (Figure $3 A$ ). No significant difference was observed between stems with $0 \%$ light exposure and those with $100 \%$ light exposure (Figure 3A). Different from one of the results obtained in the 8-week samples, in the 4-week samples, no significant difference was seen between the $50 \%$ and $0 \%$ light exposure treatments; moreover, the car/chl ratio of the $100 \%$ light exposure treatment was significantly higher $(\mathrm{p}=0.003)$ than that of the $50 \%$ light exposure treatment, opposite to the result reported for the 8 -week samples (Figure 3B). However, similar to the result in the 8-week samples, there is no significant difference between stems with $0 \%$ light exposure and those with 100\% light exposure (Figure 3B). As with the total chlorophyll content and the chl a/b ratio, no significant differences in the car/chl were observed between the three treatments in the 2-week samples (Figure 3C).

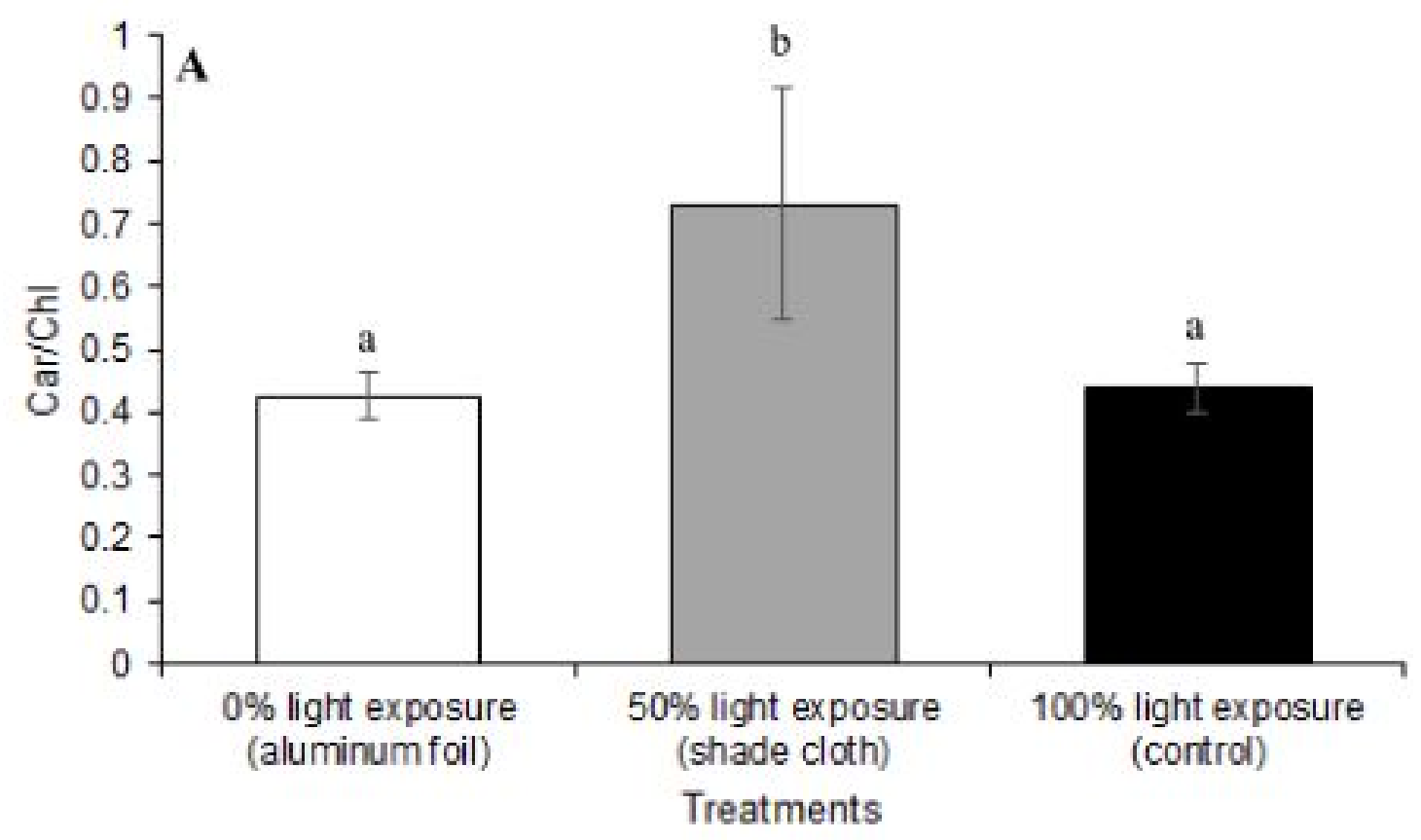



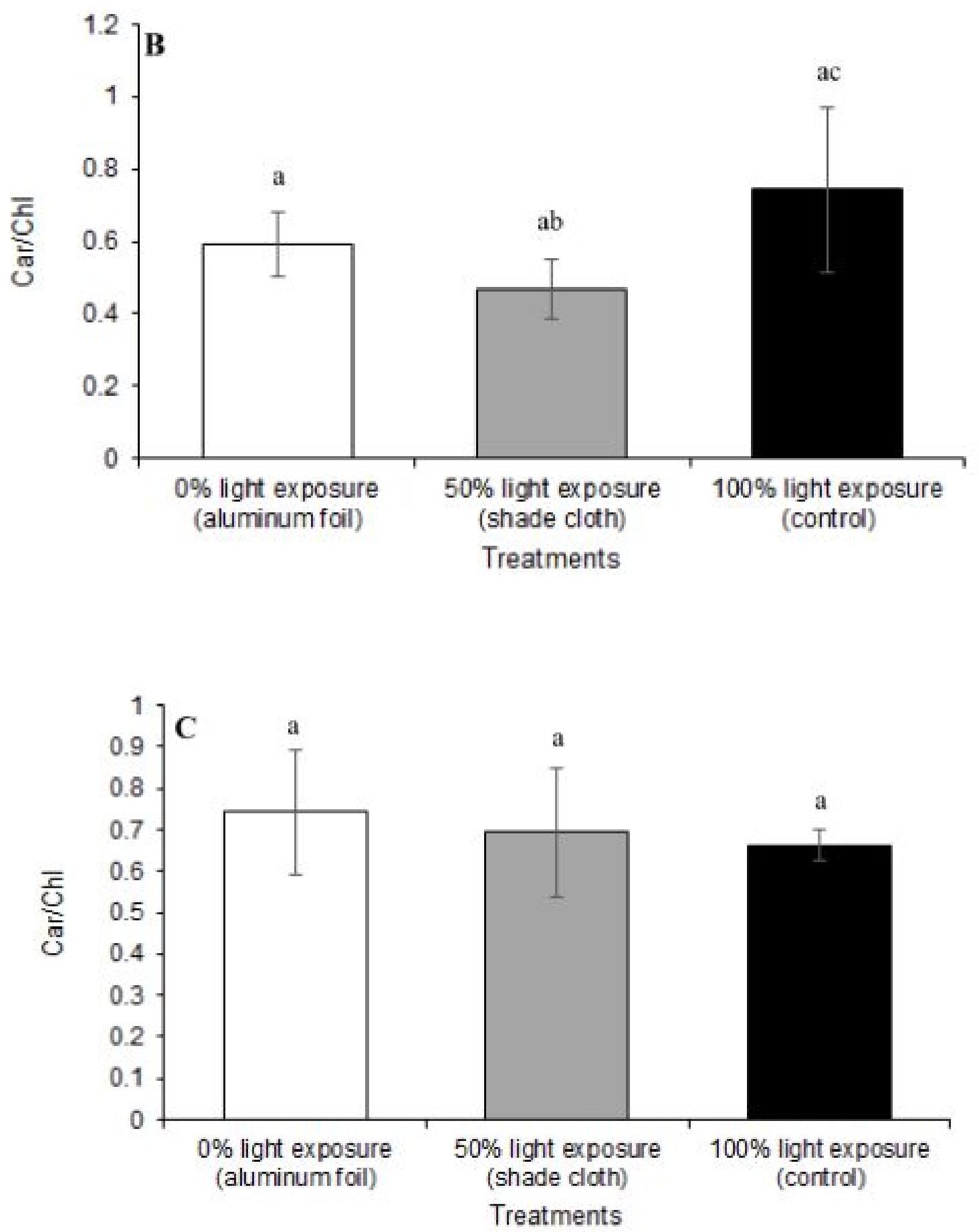

Figure 3: Mean car/chl ratio comparison between three different treatments ( $0 \%$ light exposure, $50 \%$ light exposure, and 100\% light exposure) treated for (A) 8 weeks, (B) 4 weeks, and (C) 2 weeks. Standard deviation bars are included on each of the bar graph. Means sharing the same letter are not statistically significant at the 95\% confidence level based on the LSD post hoc comparison method. 


\section{DISCUSSION}

\section{Total Chlorophyll Content and Shade Tolerance}

Chlorophyll content ( $a$ and $b$ ) tend to increase with decreasing light exposure in order to increase light harvesting in shade tolerant species (Valladares and Niinemetes, 2008). However, in the 8-week samples, the $100 \%$ light exposure treatment showed the highest total chlorophyll content, inconsistent with the aforementioned general trend. In contrast, in the 4 -week samples, the 50\% light exposure treatment showed the highest total chlorophyll content. It appeared that Fraxinus latifolia stems somewhat displayed shade-tolerant characteristic specifically in stems treated with partial sunlight exposure for only the 4-week time period. Applying shade cloth to the stems for a longer period of time (i.e 8 weeks) or completely blocking sunlight from the stems (i.e. $0 \%$ light exposure) did not yield the highest total chlorophyll content, thereby possibly indicating that prolonged low light condition and even no light exposure do not necessarily increase light harvesting in the shade tolerant Fraxinus latifolia seedlings. Nevertheless, given the inconsistent results, it is unclear if these results were due to the actual situation or due to experimental challenges. Notably, no significant differences were observed between the three treatments in the 2-week samples, suggesting that two weeks is perhaps insufficient to induce a significant response or change in chlorophyll content in the three treatments.

Striking differences were observed when comparing total chlorophyll content across different time periods. Kauppi (1991) noted that chlorophyll content of birch stems increased as early as March. Furthermore, Schaedle and Foote (1971) reported a springtime increase in chlorophyll in aspen bark. Nevertheless, in the present study, the total chlorophyll content of the $0 \%$ and $100 \%$ light exposure treatments significantly decreased by $47 \%$ and $67 \%$, respectively, from the 
8-week time period to the 4-week time period (i.e. from December to March). The sharp decline in chlorophyll content observed indicates that chlorophyll content decreases from winter to spring in Fraxinus latifolia barks. Pearson and Lawrence (1958) noted that the chlorophyll content of aspen bark decreased over the period of May to August. Thus, chlorophyll content in barks is expected to decrease not only during spring, but potentially during the summer as well.

It is important to note that the 8 -week samples were applied with aluminum foil and shade cloth and allowed to sit from December 12, 2017 to February 9,2018, the 4-week samples from February 9, 2018 to March 9, 2018, and the 2-week samples from March 9, 2018 to March 23, 2018. Because light was greatly reduced during the months of December and January, it follows that chlorophyll contents were upregulated and thus were the highest during the 8-week time period, in accordance with the general rule of shade tolerance, regarding to the $100 \%$ light exposure treatment. Barr and Potter (1974) noted that low temperature decreases chlorophyll synthesis. Thus, another explanation for the observed reduction in total chlorophyll content from December to March is that since the month of February experienced more snow than the month of December, the cold temperature from the snow during February could potentially contribute to the observed decrease in total chlorophyll content.

\section{Chlorophyll a to Chlorophyll b Ratio and Shade Tolerance}

In addition to total chlorophyll content, the ratio of chlorophyll a to $\mathrm{b}$ is a key parameter that indicates the shade tolerance of the species, that is, shade tolerant species exhibits a lower ratio compared to their counterparts exposed to high light conditions (Yamazaki et al., 2005). Due to 
the shading condition and consistent with the typical characteristic of shade tolerance, the $\mathrm{chl} \mathrm{a} / \mathrm{b}$ ratio of the $50 \%$ light exposure treatment was significantly lower than that of the $100 \%$ light exposure treatment in the 8-week samples. However, the 4-week samples yielded the opposite result: stems with $50 \%$ light exposure had a significantly higher chl a/b ratio than those with $100 \%$ light exposure. Moreover, the 2-week samples showed no significant differences between the three treatments. Thus, Fraxinus latifolia stems demonstrated shade tolerance after being subjected to a long period (i.e. 8 weeks) of shade but did not demonstrate shade tolerance after being subjected to short periods (i.e. 2 weeks and 4 weeks) of shade based on the chl a/b ratios, contradicting the result yielded from the total chlorophyll content in which Fraxinus latifolia stems demonstrated shade tolerance after being subjected to 4-week of shade in lieu of 8-week of shade. Interestingly, in all three different time periods, no significant differences were found between the two extremities, namely, between stems with $0 \%$ light exposure and those with $100 \%$ light exposure. The reverse results obtained between the total chlorophyll content and chl $\mathrm{a} / \mathrm{b}$ ratio raise the question of using high total chlorophyll content and low chl $\mathrm{a} / \mathrm{b}$ ratio as indicators of shade tolerance in general, since the range of shade tolerance varies depending on the abiotic environment at a particular time.

Similar to the trends observed across the different time periods for the total chlorophyll content, from the 8-week time period to the 4-week time period and from the 8-week time period to the 2-week time period (i.e. from December to March in both cases), the chl a/b ratio of the $100 \%$ light exposure treatment significantly decreased by $59.2 \%$ and $67.9 \%$, respectively. Low chl a/b ratio indicates that the proportion of chlorophyll $\mathrm{b}$ is higher than that of chlorophyll $\mathrm{a}$ in order to 
enhance blue light absorption under low light condition. However, the samples that displayed a decrease in chl a/b ratio were the ones with $100 \%$ light exposure and ones exposed to long period of sunlight during the spring. Thus, the result contradicted the general criteria of low $\mathrm{chl} a / \mathrm{b}$ ratio as an indicator of shade tolerance.

\section{Carotenoid to Chlorophyll Ratio and Shade Characteristic}

As a rule, shade chloroplasts typically display lower car/chl ratios because under low light environment, photo-protective beta-carotene and the components of the xanthophyll cycle are downregulated (Levizou et.al., 2004). Comparison between stems with 50\% light exposure and those with $0 \%$ light exposure in the 8 -week samples showed that the latter was significantly lower than the former which conforms to the general rule wherein low car/chl is associated with low light condition. Also consistent with the general rule, the car/chl ratio of the $100 \%$ light exposure treatment was significantly higher than that of the $50 \%$ light exposure treatment in the 4-week samples, suggesting that carotenoid production is upregulated in stems completely exposed to sunlight in order to provide photoprotection under high light condition. Thus, the stems of Fraxinus latifolia exhibited shade characteristic. However, in the 8-week samples, stems with $50 \%$ light exposure showed a significantly higher car/chl than those with $100 \%$ light exposure. Because of the unexpected result, other environmental conditions within the stems treated with $50 \%$ light exposure during the 8 -week period could possibly give rise to the unusual car/chl ratio that indicates that carotenoid production is upregulated (Levizou and Mannetas, 2007). 
Furthermore, the car/chl ratios changed significantly across different time periods. An increase in car/chl ratio indicates drought stress (Xiao, Xu, and Yang, 2008). In the present study, the car/chl ratios of stems with $0 \%$ light exposure increased by $39 \%$ from the 8 -week time period to the 4-week time period and increased by $25.5 \%$ from the 4 -week time period to the 2 -week time period. In conjunction with the increase in the car/chl ratios, the fact that the stems from the 4-week and 2-week time periods were much smaller and thinner than those in the 8-week time period could potentially indicate prolonged water deficiency due to a warmer temperature and prolonged sunlight compared to the 8-week time period. Moreover, when chlorophyll was extracted from the 4-week samples treated with $0 \%$ light exposure, the solutions were not green but were dark orange and purple, thereby possibly suggesting that other pigments associated with the photoprotective system and antioxidant system were present at high concentrations in response to water deficiency. Water deficiency is also associated with a decrease in total chlorophyll content (Xiao, $\mathrm{Xu}$, and Yang, 2008). Along with a decrease in the car/chl ratio, a decrease in total chlorophyll content across the different time periods was also observed as noted previously.

\section{CONCLUSION}

The results suggested that Fraxinus latifolia seedlings somewhat exhibited shade tolerant characteristics due to an increase in total chlorophyll content and a decrease in chl a/b ratio under partial sunlight exposure and a decrease in car/chl ratio under extreme low light condition. Notably, shade tolerant responses were displayed inconsistently across different time periods, 
thus challenging the general application of the shade tolerance criteria as the status of other environmental factors occurring over different time periods can influence shade tolerance. 


\section{ACKNOWLEDGEMENTS}

I would like to express my gratitude to my thesis advisor, Dr.Ballhorn, for guiding and helping me find a research question that was manageable for me and compatible with my level of experience, and allowing my cousin, T.Vy Tran, to assist me with laboratory work. I would also like to thank Mehmet Balkan, the lab manager, for training me on how to extract chlorophyll, use the refrigerated microcentrifuge and the spectrophotometer, and for guiding me in lab. My grateful thanks are also extended to T.Vy for her support, encouragement, and assistance with laboratory work, and to Linda Taylor, the greenhouse manager, for her help in providing the shading material for my experiment.

I would also like to thank the research group for being welcoming and helpful. In particular, I wish to express my gratitude to Brett Younginger, who let me borrowed his research greenhouse key and who often checked in with me during my laboratory work.

Finally, I extend my sincere thanks to my honors prospectus and honors continuation professors, Dr.DeLessio-Parson and Dr.Skourtes, respectively, for their writing support and to my peers for their feedback on my thesis. 


\section{REFERENCES}

Anderson, J., Chow, W., \& Park, Y. (1995). The grand design of photosynthesis: acclimation of the photosynthetic apparatus to environmental cues. Photosynthesis Research, 46(1-2):129-139.

Aschan, G., \& Pfanz, H. (2003). Non-foliar photosynthesis - a strategy of additional carbon acquisition. Flora, 198(2):81-97.

Aschan, G., Wittmann, C., \& Pfanz, H. (2001). Age-dependent bark photosynthesis of aspen twigs. Trees, 15(7):431-437.

Barr, M., \& Potter, L. (1974). Chlorophylls and carotenoids in aspen bark (Populus tremuloides). The Southwestern Naturalist, 19(2):147-154.

Beneragama, C., \& Goto, K. (2011). Chlorophyll a:b ratio increases under low-light in shade-tolerant Euglena gracilis. Tropical Agricultural Research, 22(1):12.

Cernusak, L., \& Marshall, J. (2000). Photosynthetic refixation in branches of western white pine. Functional Ecology, 14(3):300-311.

Coe, J., \& McLaughlin, S. (1980). Winter season corticular photosynthesis in Cornus florida, Acer rubrum, Quercus alba, and Liriodendron tulipifera. For. Sci, 26(4).

Einhorn, K. (2007). Growth and photosynthesis of ash Fraxinus excelsior and beech Fagus sylvatica seedlings in response to a light gradient following natural gap formation. Ecological Bulletins, (52):147-165.

Girma, A., Skidmore, A., Bie, C., Bongers, F., \& Schlerf, M. (2013). Photosynthetic bark: use of chlorophyll absorption continuum index to estimate Boswellia papyrifera bark chlorophyll content. International Journal of Applied Earth Observation and Geoinformation, 23:71-80.

Gundersen, K. (1954). Chlorophyll in young shoots of European beech (Fagus sylvatica) in winter. Nature, 174(4419):87-88.

Kauppi, A. (1991). Seasonal fluctuations in chlorophyll content in birch stems with special reference to bark thickness and light transmission, a comparison between sprouts and seedlings. Flora, 185(2):107-125. 
Levizou, E., \& Manetas, Y. (2007). Photosynthetic pigment contents in twigs of 24 woody species assessed by in vivo reflectance spectroscopy indicate low chlorophyll levels but high carotenoid/chlorophyll ratios. Environmental and Experimental Botany, 59(3):293-298.

Levizou, E., Petropoulou, Y., \& Manetas, Y. (2004). Carotenoid composition of peridermal twigs does not fully conform to a shade acclimation hypothesis. Photosynthetica, 42(4): 591-596.

Nilsen, E. (1995). Stem photosynthesis: extent, patterns, and role in plant carbon economy. Physiological Ecology, 223-240.

Owston, P. (1900). Fraxinus latifolia Benth. United States Department of Agriculture, 339-343.

Pearson, L., \& Lawrence, D. (1958). Photosynthesis in aspen bark. American Journal of Botany, 45(5):383-387.

Petritan, A., Von Lüpke, B., Petritan, I. (2007). Effects of shade on growth and mortality of maple (Acer pseudoplatanus), ash (Fraxinus excelsior) and beech (Fagus sylvatica) saplings. Forestry, 80(4):397-412.

Pfanz, H., Aschan, G., Langenfeld-Heyser, R., Wittmann, C., \& Loose, M. (2002). Ecology and ecophysiology of tree stems: corticular and wood photosynthesis. Naturwissenschaften, 89(4): 147-162.

Porra, R., Thompson, W., Kriedemann, P. (1989). Determination of accurate extinction coefficients and simultaneous equations for assaying chlorophylls $\mathrm{a}$ and $\mathrm{b}$ extracted with four different solvents: verification of the concentration of chlorophyll standards by atomic absorption spectroscopy. Biochimica et Biophysica Acta, 975(3):384-394.

Schaedle, M. (1975). Tree photosynthesis. Annual Review of Plant Physiology, 26(1):101-115.

Schaedle, M., \& Foote, K. (1971). Seasonal changes in the photosynthetic capacity of Populus tremuloides bark. For. Sci, 17(3):308-313.

Simbo, D., Van Den Bilcke, N., \& Samson, R. (2013). Contribution of corticular photosynthesis to bud development in African baobab (Adansonia digitata L.) and castor bean (Ricinus communis L.) seedlings. Environmental and Experimental Botany, 95:1-5.

Strain, B., \& Johnson, P. (1963). Corticular photosynthesis and growth in Populus tremuloides. Ecology, 44(3):581-584. 
Straumite, E., Kruma, Z., \& Galoburda, R. (2015). Pigments in mint leaves and stems. Agronomy Research, 13(4):1104-1111.

Tokarz, K., \& Pilarski, J. (2005). Optical properties and the content of photosynthetic pigments in the stems and leaves of the apple-tree. Acta Physiologiae Plantarum, 27(2):183-191.

Valladares, F., \& Niinemets, Ü. (2008). Shade tolerance, a key plant feature of complex nature and consequences. Annual Review of Ecology, Evolution, and Systematics, 39(1):237-257.

Wittmann, C., Aschan, G., \& Pfanz, H. (2001). Leaf and twig photosynthesis of young beech (Fagus sylvatica) and aspen (Populus tremula) trees grown under different light regime. Basic and Applied Ecology, 2(2):145-154.

Wittmann, C., \& Pfanz, H. (2007). Temperature dependency of bark photosynthesis in beech (Fagus sylvatica L.) and birch (Betula pendula Roth.) trees. Journal of Experimental Botany, 58(15-16):4293-4306.

Xiao, X., Xu, X., \& Yang, F. (2008). Adaptive responses to progressive drought stress in two Populus cathayana populations. Silva Fennica, 42(5).

Yamazaki, J., Suzuki, T., Maruta, E., \& Kamimura, Y. (2005). The stoichiometry and antenna size of the two photosystems in marine green algae, Bryopsis maxima and Ulva pertusa, in relation to the light environment of their natural habitat. Journal of Experimental Botany, 56(416):1517-1523. 